\title{
The importance of compounding threats to hurricane evacuation modeling
}

\author{
Jeffrey C. Cegan ${ }^{1}$, Maureen S. Golan ${ }^{1}$, Matthew D. Joyner $\mathbb{D}^{1 凶}$ and Igor Linkov (D) $^{1}$
}

Climate change and the increasing complexity of society necessitate rethinking of siloed threat scenarios in emergency response planning. Incorporating a compounding threat model into disaster response by leveraging network science techniques and dynamic data can help account for the complexity and disproportionate nature of hurricane impacts.

npj Urban Sustainability (2022)2:2 ; https://doi.org/10.1038/s42949-021-00045-7

\section{INTRODUCTION}

As increasingly complex social and infrastructure networks are overlaid with an increased probability of extreme weather events, some threats have larger than anticipated impacts, calling into question the siloed models used in emergency management for predicting community threat, vulnerability and ultimately the appropriate response plans. It goes without saying that tropical cyclones are powerful threats that should be evaluated, modeled, and regarded in their own right. But in order to comprehensively analyze and evaluate the ensuing risks and inform disaster planning, the entire underlying urban landscape-natural, infrastructure, and social-must be considered in threat models. Doing so, requires nonlinear thinking and employing compounding threat models.

Late 2020 in Louisiana provides a poignant example: chemical plants, social and built-environment disparities, and a pandemic added to the backdrop of aging infrastructure and climate change that met Hurricane Laura, the most expensive "billion-dollar" weather event of the year ${ }^{1}$. And nationally, the predicted $\$ 54$ billion of hurricane damages by the Congressional Budget Office in 2019 fell short of the actual $\$ 60-\$ 65$ billion of damages in $2020^{2,3}$. Despite improved forecasting and hurricane evacuation preparedness, the increased complexity of threat and vulnerability make evacuations and recovery more difficult to plan for, and ultimately more expensive ${ }^{4}$. This is because the threats and vulnerabilities that hurricanes pose cannot be considered independently of other weather events and the unique circumstances of the areas they affect.

Our current work in support of COVID response and recovery ${ }^{5-7}$ developments by others in the risk and decision-making field ${ }^{8,9}{ }^{\prime}$, and new thinking stemming from the occurrence of disruptions during the SARS-CoV-2 pandemic ${ }^{10-14}$, has highlighted the need for incorporation of a compounding threat framework into disaster response plans. The compounding threat framework leverages the nonlinear nature of threats, vulnerability, and response into a combined model for improved decision making. In modeling the true dynamics and interrelations of threat and response, more equitable, efficient, and resilience-based systematic decisions can be made for emergency management, including hurricane evacuations. With the increased number of predicted storms for the 2021 Atlantic hurricane season ${ }^{4}$, leveraging dynamic models with existing emergency response strategies is imperative for resilient communities.

\section{HURRICANE THREATS ARE NOT SILOED}

Risk assessment and management typically considers individual threats using historic data or model predictions; multiple threats can be added in all-hazards frameworks ${ }^{15}$. However, this approach neglects the interconnections of real systems (e.g., urban environments and climate change), and the cascading and nonlinear nature of certain threats (e.g., hurricanes). The idea for first approaching the impacts of hazards on real systems from a compounding threat approach was introduced by the Intergovernmental Panel on Climate Change (IPCC) in order to account for increasing climate drivers ${ }^{16}$. The IPCC therefore considers three basic definitions of compounding threats: (1) two or more extreme events occurring simultaneously or successively; (2) extreme events with underlying conditions that amplify the impacts; and (3) two or more events that may not themselves be extreme, but when occurring simultaneously have larger impacts ${ }^{16}$.

In general, the framework has been expanded to account for geographic and temporal drivers in addition to climate change that may interact with each other in a manner that exacerbates expected outcomes ${ }^{17}$. For example, for hurricanes, inland flooding is often underestimated despite the fact that the hurricane rainfall and storm tides in combination cause observed compound flooding that is more severe than models predict ${ }^{18}$. And of course, the more recent co-occurrence of the hurricane season and the COVID-19 pandemic compound the individual hazard that each poses independently.

In addition to pandemics and disease outbreaks, the IPCC compounding threat framework can also be extended to humancaused disasters such as warfare, political instability, or financial crisis $^{19}$. However, these natural disaster, climatic events, and even man-made events also interact with pre-existing socioeconomic conditions and other baseline realities, or vulnerabilities.

\section{HURRICANE VULNERABILITY IS NOT SILOED}

Differential vulnerabilities among communities can lead to catastrophic impacts in more susceptible populations, with preimpact hurricane damage predictions often inaccurately quantifying the post-disaster damage experienced ${ }^{20,21}$. For example, longterm exposure to air pollution (measured by particulate matter $\mathrm{PM}_{2.5}$ ), which is more likely to plague lower income and marginalized communities due to systemic racism and factors such as proximity to industrial areas and busy roads, has been positively associated with higher COVID-19 mortality rates in the U.S. ${ }^{22,23}$.

${ }^{1}$ U.S. Army Engineer Research and Development Center, Vicksburg, MS, USA. ${ }^{凶}$ email: Matthew.D.Joyner@usace.army.mil 
Air pollution is therefore interacting with the SARS-CoV-2 pandemic manifestation in certain communities, compounding their expected negative health impacts.

Just as resilience to disease outbreaks are functions of the underlying social fabric ${ }^{24,25}$, hurricane vulnerabilities cannot be accurately modeled without factoring in poverty, food insecurity, and other social burdens ${ }^{12,26}$. For hurricanes, this could include preexisting hazards such as coastal erosion, which when analyzed together with social, economic, built environment and other physical indicators impact overall community vulnerability ${ }^{27}$. Without the union of these components, policies are incomplete, and mitigation plans untenable ${ }^{27}$. In other words, a one-size-fit-all approach to preparedness, response, and recovery fails to maximize emergency management effectiveness due to compounded vulnerabilities, often leaving poorer communities particularly exposed ${ }^{19,21}$. As such, modeling the compounding risks into the response plans is necessary.

\section{HURRICANE RESPONSES SHOULD NOT BE SILOED}

In direct extension to our hurricane evacuation tool development, we have found that the first step towards complementing existing hurricane evacuation strategies is through dynamicity, whereby the emergency manager has the ability to incorporate new community variables as they become available, rather than relying on historic trends and city plans/layouts that dictates variables such as evacuation zones, clearance times, public sheltering locations and shelter demand. This enables real-time decision evaluation and synthesis of tradeoffs in policy targets, allowing for social distancing, vulnerable populations (e.g., mobile home population, people with disabilities, etc.) and critical infrastructure surge zones, for example, to be explicitly considered. The SARSCoV-2 pandemic's severity during the 2020 hurricane season highlighted the need for contextual disaster response and the importance of incorporating compounding threat frameworks into emergency management procedures, as communities experienced simultaneous disruptions which exacerbate pre-existing characteristics, from inadequate resilience in infrastructure to poverty and health risks (see Fig. 1). These compounded impacts then need to be incorporated into response plans and emergency management protocols, such as hurricane evacuation. Further understanding and modeling of compound threats, and formally complementing existing hurricane evacuation plans with such a framework will enable tailored and improved overall community response and resilience.
These nonlinear interactions must be accounted for not only when modeling the anticipated impacts of natural disasters, such as hurricanes, but also in their management and emergency response planning. For example, in response to the unprecedented co-occurrence of the SARS-CoV-2 pandemic with the hurricane season, the U.S. Federal Emergency Management Agency (FEMA) issued updated evacuation guidelines for evacuation and sheltering to be considered with the standard "least-risk decision making" framework established by the American Red $\mathrm{Cross}^{28,29}$. This dual-threat and vulnerability of COVID-19 and a natural disaster-hurricanes in this instancepresents a clear need for compound threat thinking in emergency management and evacuation response plans and implementation $^{30}$. However, implementation frameworks that extend from the modeling of the threat and vulnerability to the ultimate emergency response remain limited.

\section{COMPOUNDING THREAT MODELS CAN HELP EVACUATIONS}

The growing body of work surrounding compound threats provides a framework for incorporating reality's interdependent hazards into viable interdependent responses ${ }^{19,31,32}$. The field acknowledges the fact that the impacts of two or more disruptions taken in context may be greater than the sum of their impacts taken independently. This facilitates incorporation of concurrent, systemic or otherwise complex threat interactions into emergency management models, aligning short-term and long-term response and recovery with the reality of community impacts from multiple hazards. Complementing existing emergency management practices and risk mitigation tools with a compounding threat framework leverages the fact that hurricane evacuations should not be siloed, and should be considered within the context of all possible sources of threats, stemming from their natural, infrastructure, and socioeconomic environments.

As threats and vulnerabilities become more compounding, evacuations must follow suit. The traditionally siloed nature of emergency management must leverage accessible models and quantitative methods to assess true impacts, risk, and response needs, in order to make communities resilient to hurricanes. One approach to incorporating compounding threats is through the development of dynamic evacuation tools that are capable of adjusting inputs and outputs on a case-by-case basis. Dynamic inputs, such as employment levels of residents, age groups, road construction, flood maps, hospitalization rates, and other location

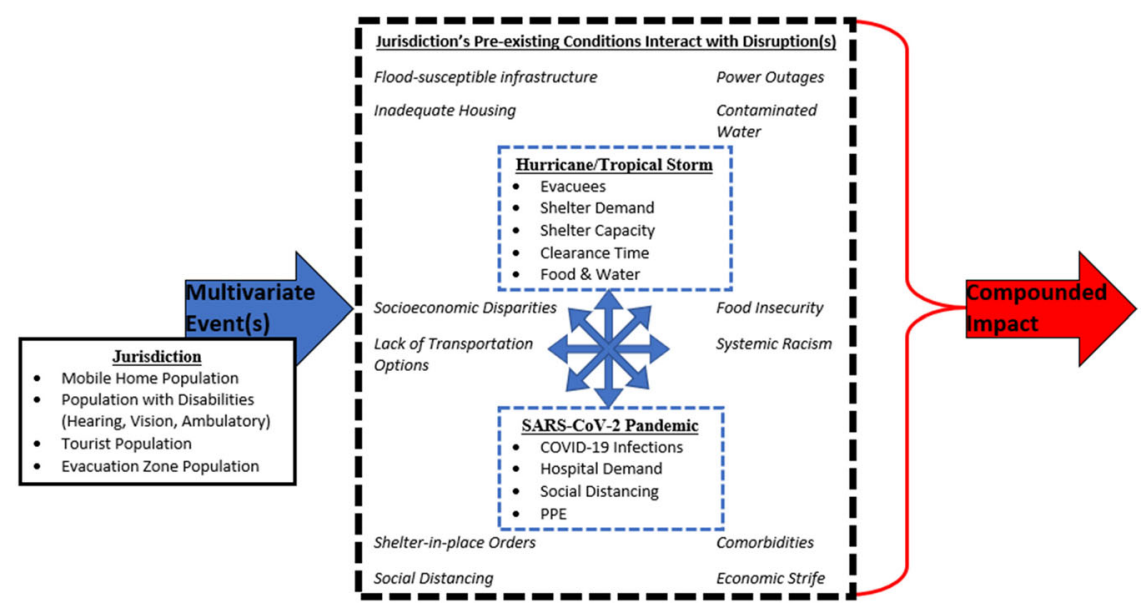

Fig. 1 Overview of the compounding threats arising from the confluence of the SARS-CoV-2 pandemic and the 2020 hurricane season. Notional community's vulnerable population for hurricane evacuation (solid black line) experiencing compounding threats from acute disruptions (blue dashed line) and pre-existing disruptions (dashed black line) leading to compounding impacts through layered and exacerbating connections and system processes. 
and time specific variables can be adjusted when a hurricane is approaching to tailor an evacuation response accordingly. This can either be done manually with a tool or dashboard, or through the use of computer-aided processes such as a software that pulls from other databases. Machine learning (ML) algorithms could also be used to fully take advantage of the most current threat and vulnerability information as public databases may not always be kept up to date.

The second proposed approach is network science and the underlying systems thinking and analysis, which can incorporate threat, vulnerability, and response links/connections/flows across space and time ${ }^{33}$. This modeling approach is powerful because it embraces the interconnections and complexities that systems face, enabling quantification of the compounding nature of reality's hurricanes and informing planning for a cohesive response given limited resources.

Although employing network science in response planning for compound threats remains in its infancy, one study analyzed resilience of the London Rail Network to flooding similar to that of the flooding of the New York subway from Hurricane Sandy in $2012^{34}$. The researchers modeled the flooding in conjunction with a targeted cyber-physical attack finding that many of the dependent networks, or less obvious connections outside of the direct system, suffered disproportionately severe cascading failure. Significantly, Yadav et al. ${ }^{34}$ extend the work of others leveraging spatial and network science methodologies ${ }^{35-37}$ to underscore the importance of network science as a valuable organizing principal for post-disruption recovery in the face of complex disruptions.

For example, directly tying the network science methodology to a resilience metric (e.g., time to recovery) allows the compounding nature of the hurricane impacts, risks, and responses to be cohesively modeled, allowing emergency managers, stakeholders, the public, and policymakers to implement proactive corrective actions that enable absorption, recovery and adaptation to disruptive events. Leveraging artificial intelligence (AI) and ML capabilities for the network science model is one method of making sense of the large datasets required to map the vast complexities of these compounding interactions and uncertainties. For example, employing $\mathrm{Al} / \mathrm{ML}$ in modeling the impacts of successive hurricanes on the electric grid can inform improvements to not only the resilience of the grid itself to compounding threats, but also the resilience of the socioeconomic functions that rely on electricity ${ }^{38}$.

Incorporating network modeling approaches in tandem with resilience analytics can facilitate improved characterization of the interactions and uncertainties that comprise real threats, leading to better frameworks for approaching compounding risks, emergency management, and ultimately saving lives and improving livelihoods ${ }^{19,25}$. In so doing, disaster policies and hurricane evacuation plans can leverage the compounding threat framework, promoting equity, efficiency, and resilience into existing emergency management strategies.

As climate change, globalization, aging infrastructure, disease outbreaks, and systemic racism and other inequalities continue to add complexity to disaster management, hurricane evacuations need to consider the myriad of threats in a compounding framework. Leveraging real time data capabilities for dynamic models and employing a network science approach can facilitate a deeper understanding of the true compounding nature of hurricanes and their evacuations.

\section{DATA AVAILABILITY}

No datasets were generated or analyzed during the current study.
Received: 27 June 2021; Accepted: 3 December 2021;

Published online: 10 January 2022

\section{REFERENCES}

1. NOAA National Centers for Environmental Information (NCEI). U.S. Billion-Dollar Weather and Climate Disasters. https://www.ncdc.noaa.gov/billions/ (2021).

2. Congressional Budget Office ( $\mathrm{CBO}$ ). Expected costs of damages from hurricane winds and storm-related flooding. In Proc. Congress of the United States Congressional Budget Office, Publication 55019 (2019).

3. Puleo, M. Record-breaking 2020 hurricane season caused $\$ 60$ billion to $\$ 65$ billion in economic damage. AccuWeather 25 Sep 2021. https://www.accuweather. com/en/hurricane/record-breaking-2020-hurricane-season-caused-60-billion-to65-billion-in-economic-damage/858788 (2020).

4. National Oceanic and Atmospheric Administration (NOAA). 'Average' Atlantic Hurricane Season to Reflect More Storms. U.S. Department of Commerce. 9Apr2021. https://www.noaa.gov/media-release/average-atlantic-hurricane-season-to-reflectmore-storms (2021).

5. Trump, B. D. et al. An analytical perspective on pandemic recovery. Health Secur. 18, 250-256 (2020)

6. Linkov, I., Keenan, J. \& Trump, B. D. COVID-19: Systemic Risk and Resilience. 1st edn (Springer, Amsterdam, 2021).

7. Galaitsi, S. E. et al. The challenges of data usage for the United States' COVID-19 response. Int. J. Inform. Manage. 59, 102352 (2021).

8. Anderson, K. et al. After the hurricane: validating a resilience assessment methodology. Int. J. Disaster Risk Reduct. 51, 101781 (2020).

9. Liu, M. \& Huang, M. C. Compound disasters and compounding processes: implications for disaster risk management. The United Nations Office for Disaster Risk Reduction, Global Assessment Report on Disaster Risk Reduction (2014).

10. Centers for Disease Control and Prevention (CDC). Hurricane key messages: COVID-19 Annex: preparing for hurricanes during the COVID-19 pandemic. U.S Department of Health and Human Services. 11 Aug 2020; CS318076A (2020).

11. Pei, S., Dahl, K. A., Yamana, T. K., Licker, R. \& Shaman, J. Compound risks of hurricane evacuation amid the COVID-19 pandemic in the United States. Geohealth. 4, e2020GH000319 (2020).

12. Office for the Coordination of Humanitarian Affairs (OCHA). Global Humanitarian Overview 2021. United Nations. https://reliefweb.int/sites/reliefweb.int/files/ resources/GHO2021_EN.pdf (2020).

13. Dargin, J., Garcia, S., Oztekin, B. \& Mostafavi, A. Compound Pandemic and Hurricane Hazard Index (CPHI) overview. Urban resilience. Al Lab, Texas A\&M University (2020).

14. Hynes, W., Trump, B. D., Love, P. \& Linkov, I. Bouncing forward: a resilience approach to dealing with COVID-19 and future systemic shocks. Environ. Syst. Decis. 40, 174-184 (2020).

15. Abkowitz, M. D. \& Chatterjee, S. Regional disaster risk: assessment and mitigation concepts in an all-hazards context. J. Homel. Secur. Emerg. Manag. 9, 15 (2012).

16. Intergovernmental Panel on Climate Change (IPCC). Managing the Risks of Extreme Events and Disasters to Advance Climate Change Adaptation. A Special Report of Working Groups I and II of the Intergovernmental Panel on Climate Change [Field, C. B. et al. (eds.)]. Cambridge University Press, Cambridge, UK, and New York, NY, USA, 582 pp (2012).

17. Zscheischler, J. et al. Future climate risk from compound events. Nature Clim. Change 8, 469-477 (2018).

18. Gori, A., Lin, N. \& Xi, D. Tropical cyclone compound flood hazard assessment: from investigating drivers to quantifying extreme water levels. Earth's Future 8, e2020EF001660 (2020).

19. The World Bank. Global Crisis Risk Platform (English). Washington, D.C.: World Bank Group. http://documents.worldbank.org/curated/en/762621532535411008/ Global-Crisis-Risk-Platform (2018).

20. Szczyrba, L., Zhang, Y., Pamukcu, D., Eroglu, D. I. \& Weiss, R. Quantifying the role of vulnerability in hurricane damage via a machine learning case study. Nat. Hazards Rev. 22, 04021028 (2021).

21. Cutter, S. \& Emrich, C. T. Moral hazard, social catastrophe: the changing face of vulnerability along the hurricane coasts. Ann. Am. Acad. Pol. Soc. Sci. 604, 102-112 (2006)

22. Walensky, R. P. Director's Commentary. Racism and Health, Minority Health and Health Equity. U.S. Centers for Disease Control and Prevention (CDC), 8 April 2021. https://www.cdc.gov/healthequity/racism-disparities/director-commentary. html (2021).

23. Wu, X., Nethery, R. C., Sabath, M. B., Braun, D. \& Dominici, F. Air pollution and COVID-19 mortality in the United States: strengths and limitation of an ecological regression analysis. Sci. Adv. 6, eabd4049 (2020).

24. Massaro, E., Ganin, A., Perra, N., Linkov, I. \& Vespignani, A. Resilience management during large-scale epidemic outbreaks. Sci. Rep. 8, 1859 (2018). 
25. Linkov, I. \& Trump, B. D. The Science and Practice of Resilience. 1st edn (Springer, Amsterdam, 2019).

26. Schmidtlein, M. C., Deutsch, R. C., Piegorsch, W. W. \& Cutter, S. L. A sensitivity analysis of the social vulnerability index. Risk Anal. 28, 1099-1114 (2008).

27. Boruff, B. J., Emrich, C. \& Cutter, S. L. Erosion hazard vulnerability of US coastal counties. J. Coast. Res. 21, 932-942 (2005).

28. Federal Emergency Management Agency (FEMA). Mass care/emergency assistance pandemic planning considerations: for state, local, tribal, territorial, and non-government organizational planners, providers and support agencies. U.S. Department of Homeland Security (2020).

29. American Red Cross (ARC). Standards for Hurricane Evacuation Shelter Selection (ARC 4496). (2002)

30. Mostafavi, A. Hurricanes and wildfires are colliding with the COVID-19 pandemic - and compounding the risks. The Conversation. https://theconversation. com/hurricanes-and-wildfires-are-colliding-with-the-covid-19-pandemic-andcompounding-the-risks-145003 (2020).

31. Smith, A. B. 2020 U.S. billion-dollar weather and climate disasters in historical context. Climate.gov. National Oceanic and Atmospheric Administration (NOAA). 8 Jan 2021. https://www.climate.gov/news-features/blogs/beyond-data/2020-usbillion-dollar-weather-and-climate-disasters-historical (2021).

32. Ridder, N. N. et al. Global hotspots for the occurrence of compound events. Nat. Commun. 2020, 5956 (2020).

33. Kott, A. \& Linkov, I. Cyber Resilience of Systems and Networks. 1st edn (Springer International Publishing, New York, NY, 2019).

34. Yadav, N., Chatterjee, S. \& Ganguly, A. R. Resilience of urban transport network-ofnetworks under intense flood hazards exacerbated by targeted attacks. Sci. Rep. 10, 10350 (2020).

35. Duan, D. et al. Universal behavior of cascading failures in interdependent networks. Proc. Natl. Acad. Sci. U.S.A. 116, 22452-22457 (2019).

36. Hong, S., Zhu, J., Braunstein, L., Zhao, T. \& You, Q. Cascading failure and recovery of spatially interdependent networks. J. Stat. Mech. 2017, 103208 (2017).

37. Kurth, M. et al. Lack of resilience in transportation networks: economic Implications. Transp. Res. D Transp. Environ. 86, 102419 (2020).

38. Dehghani, N. L., Jeddi, A. B. \& Shafieezadeh, A. Intelligent hurricane resilience enhancement of power distribution systems via deep reinforcement learning. Appl. Energy 285, 116355 (2021).

\section{ACKNOWLEDGEMENTS}

The authors are grateful to Marco Ciarla of the National Hurricane Program and Melissa Surette of FEMA for additional guidance regarding current evacuation and sheltering practices. This study was funded in parts by the US Army Engineer Research and Development Center (ERDC) Future Innovation Funding Program on
"System Resilience in Response to Systemic and Compounding Threats" as well as the National Hurricane Program. The views and opinions expressed in this paper are those of the individual authors and not those of the US Army or other sponsor organizations.

\section{AUTHOR CONTRIBUTIONS}

JCC, MSG, MDJ, and IL each contributed with substantial input to the core content and framing of the paper. MSG wrote the first draft of the text and developed the figure. All authors reviewed and edited the final version. JCC proposed the initial idea and contributed with project administration.

\section{COMPETING INTERESTS}

The authors declare no competing interests.

\section{ADDITIONAL INFORMATION}

Correspondence and requests for materials should be addressed to Matthew D. Joyner.

Reprints and permission information is available at http://www.nature.com/ reprints

Publisher's note Springer Nature remains neutral with regard to jurisdictional claims in published maps and institutional affiliations.

(i) Open Access This article is licensed under a Creative Commons Attribution 4.0 International License, which permits use, sharing, adaptation, distribution and reproduction in any medium or format, as long as you give appropriate credit to the original author(s) and the source, provide a link to the Creative Commons license, and indicate if changes were made. The images or other third party material in this article are included in the article's Creative Commons license, unless indicated otherwise in a credit line to the material. If material is not included in the article's Creative Commons license and your intended use is not permitted by statutory regulation or exceeds the permitted use, you will need to obtain permission directly from the copyright holder. To view a copy of this license, visit http://creativecommons. org/licenses/by/4.0/.

(c) The Author(s) 2022 